\title{
Willingness to Pay For Community Based Health Care Financing Scheme: A Comparative Study among Rural and Urban Households in Osun State, Nigeria
}

\author{
Dr Usman, Aishat Bukola \\ Department of Community Medicine, LAUTECH Teaching Hospital, Oshogbo, Osun State, Nigeria
}

\begin{abstract}
Background: Out-of-pocket payment dominates the bulk of health care financing in Osun State as in other parts of Nigeria. Pre-payment plans which have been identified to turn the unexpected health expenditures into predictable form of payments have not received desirable consideration. Given the importance of such prepayment scheme, the aim of this study is to assess willingness to pay for community based health care financing scheme among rural and urban households in Osun State.

Methodology: This is a descriptive, cross-sectional comparative study of willingness to pay for community based health care financing schemes among 450 urban and an equal number of rural households in Osun State using multistage sampling method. Research instruments were pre-coded, pre-tested semi structured interviewer administered questionnaire. Data were analysed using STATA 10 software.

Result: The findings from this research showed that rural household heads 373 (82.8\%) were more willing to pay for community based health care financing scheme than the urban household heads 232 (51.6\%). Premium Urban households were willing to pay $\$ 1798.90 \mathrm{k}$ per year while rural ones were willing to pay $721.70 k$.

Major factors identified that contribute to willingness to pay in the households are number in the households, level of education, income, distance to the health centers, marital status, age and Male gender.

Conclusion: Women, the poor, and people with low level of education were less willing to pay. Therefore, when establishing community based health scheme there should be selective targeting of the vulnerable groups within the communities due to their inability to finance health care payments.

The results of this research strongly suggest that contingent valuation surveys are feasible methods for estimating households'willingness to pay for community based health care financing scheme in Osun State.

Keywords: Willingness to pay, Community based Health Care Financing, Nigeria
\end{abstract}

\section{ARTICLE FOCUS}

- This study is on health care financing in Nigeria as a developing nation

- Are household heads willing to pay for community based health care financing scheme?

- How much are household heads willing to pay for community based health care financing scheme?

- What are the factors contributing to willingness to pay for community based health care financing scheme in Osun state, Nigeria.

\section{KEY MESSAGES}

- Out of pocket payment for health care in Osun state contribute over $70 \%$ of health expenditure as well as in Nigeria as a whole.

- Community based health care financing as have been established in some resource poor countries and have been proffered to be a viable option as a means of safeguarding the poor from huge burden of medical bills.

- This study examines willingness to pay for community based health care financing scheme among rural and urban households in Osun State Nigeria.

STRENGTH AND LIMITATION

- Majority (82.8\%) of the rural households were willing to pay for community based health care financing scheme.

- The premium households were willing to pay was small for the sustainability of the scheme

- The study did not distinguish public and private health care providers in the willingness to pay questions; this could probably be the major limitation of the study

\section{Introduction}

The health care financing refers to the collection of funds from various sources, pooling of funds and distribution of risk across larger groups of people, as well as the allocation or use of funds for purchase of services among public and private health care . ${ }^{1}$ Although many countries have endorsed the principles of 
Bamako initiative and integrated its objectives in their national health policy, access to health care did not improve on the long term. ${ }^{2}$

Community Based Health care financing is needed as an alternative for financing health care. The objective is to enable low -income people to work together and contribute resources to meet their health care needs and fair access to health care needs and fair access to healthcare.

Majority of Nigerians cannot afford and access health care services because it is beyond their reach, statistics puts $70.2 \%$ of Nigerians as living below the poverty line of USD 1.00 per day which encourages the vicious cycle of poverty, ignorance and disease. There is high dependence and pressure on government for funding of health services, a situation which the government has objectively not lived up to in recent years. Government expenditure on health is USD 3.40 per capita as opposed to the World Developmental Report recommendation of USD 34 per capita. ${ }^{3}$ The continued stagnating healthcare system in Nigeria is of great social and economic consequence, as the deregulation of healthcare financing and supply in Nigeria has further shifted the healthcare system towards competitive market ideals. ${ }^{4}$ Thus an urgent need for a sustainable and equitable strategy to eliminate physical and financial barriers to health care is highly desired.

One novel approach to increasing coverage for the people is Community-Based Health financing which is a non-profit arrangement for the informal sector formed on the basis of an ethic of mutual aid and the collective pooling of health risks and resources which members of the community are responsible for its management. Community-Based Health Financing scheme is an alternative mechanism to providing access for the poor, unemployed and those living in the rural areas; most of who are not under the NHIS nor any private health insurance scheme that could provide financial protection against illness. Since CBHF has proven to be an attractive option in funding the health systems of most developing countries ${ }^{5}$, there is need to scale-up the community-based health financing scheme in Nigeria. This scheme has the potential to address the issue of inadequate funding of the health system. With this scheme, a larger percentage of the population would be covered thereby achieving the objectives for which the National Health Insurance Scheme was established by government.

Community health care financing may be defined as voluntary contributions made by individuals, families, or community groups to support the cost of health care services, with particular emphasis on primary health care. ${ }^{5}$ This support may cover partially or fully the cost of running such services. The contributions could be in cash, kind, or labor. Community financing alternatives include private donations; community contributions in kind; special fund-raising events; income-generating schemes; and individual fees for service in form of prepayment, standard payment for all services, payment for cost of materials. ${ }^{5}$ Unlike many insurance schemes, CBHF schemes are typically based on the concepts of mutual aid and social solidarity and are typically designed by and for people in the informal and rural sector who are unable to get adequate public, private, or employersponsored health insurance. ${ }^{6}$

Well organized and sustained small CBHF schemes can develop to strong and acceptable social health insurance system. This is true of the health insurance systems currently operating in Germany, Japan, and Korea. ${ }^{5}$ Today's CBHF schemes are operated in a manner similar to the friendly societies which existed in large numbers in the United Kingdom during the 19th century or and also the traditional solidarity welfare mechanisms in West Africa. ${ }^{5}$

\subsection{General and Specific Objectives \\ 1.4.1 General objective}

To determine the level, and compare the willingness of households in rural and urban communities in Osun State to pay for community based health care financing scheme.

\subsubsection{Specific objectives}

1. To assess the willingness of household heads to pay for community based health care financing scheme in rural and urban areas, in Osun State.

2. To determine the premium that rural and urban households are willing to pay for community based health care financing scheme in the study areas.

3. To identify major factors that contribute to willingness to pay for community based health care financing scheme in these rural and urban areas.

\subsection{Theoretical Models for Assesment of WTP}

From the neo-classical theory of welfare economics point of view, which incorporates the preference of individual/households, where interest lies in obtaining monetary values for any changes in welfare (gain or lost) due to the availability of a specific public good, or in case of health and health care, changes in the states of health led to the use of the willingness to pay (WTP) and willingness to accept (WTA), which are often referred to as methods of contingent valuation (CVM) ${ }^{24}$ Originally used in the theory of welfare economics to analyze price changes, Karl-Groan first showed that the concept could be employed to analyze quantity changes. Closely 
related to the theory of consumer demand, the maximum amount an individual is WTP gives the value of a health intervention aimed at improving the state of health of the individual. ${ }^{24}$

The goal of contingent valuation is to measure the compensating or equivalent variation for the good in question. Compensating variation is the appropriate measure when the person must purchase the good, such as an improvement in health quality. Equivalent variation is appropriate if the person faces a potential loss of the good, as he would if a proposed policy results in the deterioration of health quality. Both compensating and equivalent variation can be elicited by asking a person to report a willingness to pay amount. For instance, the person may be asked to report his WTP to obtain the good, or to avoid the loss of the good. Formally, WTP is defined as the amount that must be taken away from the person's income while keeping his utility constant:

$\mathrm{V}(\mathrm{y}-\mathrm{WTP}, \mathrm{P}, \mathrm{q} 1 ; \mathrm{Z})$

Where $V$ denotes the indirect utility function, $y$ is income, $p$ is a vector of prices faced by the individual, and $q_{0}$ and $q_{1}$ are the alternative levels of the good or quality indexes (with $q_{1}>q_{0}$, indicating that $q_{1}$ refers to improved health quality).

Willingness to accept for a good is defined as the amount of money that must be given to an individual experiencing deterioration in environmental quality to keep his utility constant:

$\mathrm{V}(\mathrm{y}+\mathrm{WTP}, \mathrm{P}, \mathrm{qo} ; \mathrm{Z})$

In equations (1) and (2), utility is allowed to depend on a vector of individual characteristics influencing the trade-off that the individual is prepared to make between income and health quality. An important consequence of equations (1) and (2) is that WTP or WTA should, therefore, depend on;

(i) The initial and final level of the good in question $\left(q_{0}\right.$ and $\left.q_{1}\right)$;

(ii) Respondent income;

(iii) All prices faced by the respondent, including those of substitute goods or activities; and

(iv) Other respondent characteristics. Internal validity of the WTP responses can be checked by regressing WTP on variables (I)-(IV), and showing that WTP correlates in predictable ways with socio-economic variables. Assume households to be risk averse in demanding for healthcare and employing utility income graph, also assuming that utility or wellbeing is dependent on income and health. The amount a household will be WTP for community based health care financing will be the amount of income an individual is willing to part with still leaving the household at same level of well being before the community based health financing scheme. The maximum amount a household is WTP for improvement in health status is defined as the gap between yo and y1(yo-y1) as shown in the graph below.

(Utility)

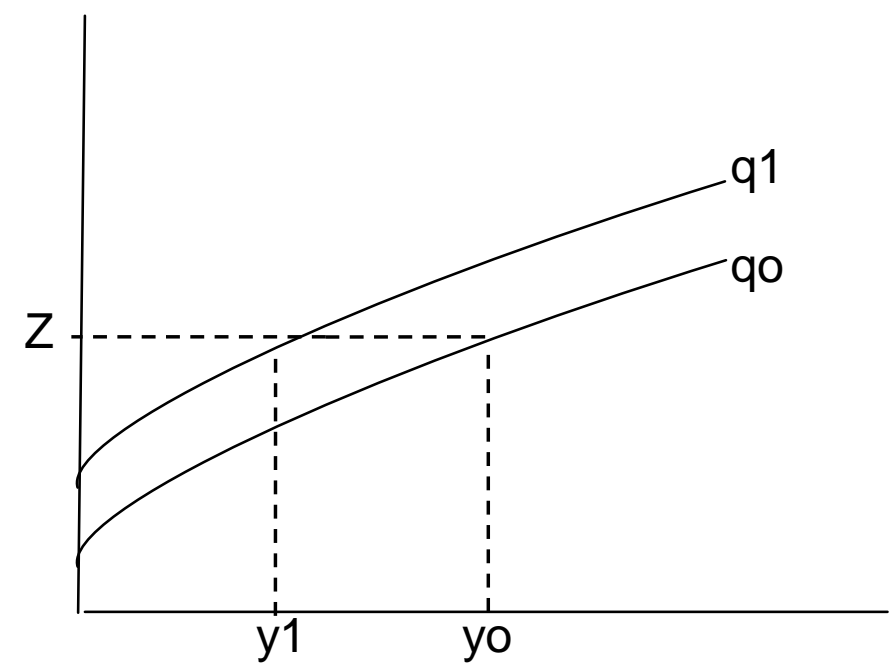

Figure 1: The amount Households are WTP for an improvement in health status still maintaining the same level of well being Z. ${ }^{22}$

qo denotes the original level of health status and q1 denotes the improvement in health status. The income level at improved health status is lower $(\mathrm{y} 1<\mathrm{yo})$ due to the payment though the household still maintain the same level of utility or well being constant $Z$. If the household had to pay higher than yo-y1,then the loss in income will be more than offset the increase in we

\subsection{Review of Literatures on Household's Willingness to Pay for Community Based Health Care Financing Scheme.}

A study was conducted in pakistan with the objectives to determine the demand for health care services in the community; at first level care facilities and community level and determine the willingness of the 
community (Willingness to pay) to participate in cost sharing mechanisms for provision of primary health care in fee for service and prepayment mechanisms. A cross sectional stratified household interview survey of 600 households was carried out in urban and rural areas of district Jhelum, to address the financial sustainability of government health care interventions at the community level and to explore the question of willingness to pay for health care and their ability to participate in the cost sharing mechanisms.

In response to willingness to pay at a Government facility to obtain health care $437(72.7 \%)$ of the households expressed their willingness to pay for health care. In $72 \%$ of the cases, cost was not considered as a barrier in seeking care and only $19 \%$ of the cases considered cost as a partial barrier; the rest said that cost prohibited seeking care. A majority across all strata is willing to pay for consultation and medicines at public sector facilities, although the responses from the low income groups exhibit a slight decrease in the willingness to pay. The willingness to pay is marginally affected by income, place of residence and/or cost of the treatment incurred ${ }^{7}$ In Nigeria, a study on willingness to pay for health insurance among rural and urban residents of Enugu and Imo states shows that less than $40 \%$ are willing to pay for CBHI membership for themselves or other household members. The proportions of people who are willing to pay were much lower in the rural communities, at least less than $7 \% .^{8}$ Another study from North Central Nigeria among rural heads of households found out that $87 \%$ are willing to pay for community based health insurance ${ }^{9}$

\subsubsection{Premiums Households are Willing to Pay for Community Based Health Care Financing Scheme based on Previous Studies}

A study by Barnighausten et al examined WTP among informal sector workers in Wuhan, China; found that these workers are willing to pay the equivalent of 4 US Dollars per person per month. ${ }^{10}$ Another study in India used unidirectional bidding in a Contingent Valuation(CV) survey to obtain estimates of WTP for health insurance. In this study the median WTP for health insurance is the equivalent of 15 US Dollars per household per month ${ }^{11}$ In rural Iran, the finding was that households are willing to pay three US Dollars per household per month on the average ${ }^{.12}$ In a similar study on WTP for a school based chemotherapy program in Tanzania, greater than seventy percent had WTP greater than 1.25 United States Dollars. ${ }^{13}$

In the survey five percent of respondents were not willing to pay any money for the scheme;twenty-five percent of the respondents were willing to pay between 0.1 and 1.24 US Dollars while $70 \%$ were willing to pay 1.25 US Dollars and above. ${ }^{13}$ In a related study on WTP for cataract surgery in Tanzania the amount patients reported that they were willing to pay ranged from 0 to 18.75 US Dollars (USD) per person per surgery.The mean was three US Dollars and the standard deviation was six USD. ${ }^{14}$ A study in Namibia revealed fairly higher WTP of seven USD per person per month. ${ }^{15}$ Rural Nigeria studies are also available on WTP. Ichoku et al found a WTP of 1.5 USD per household per month. ${ }^{16}$

On the other hand Onwujekwe et al in a Nigerian survey found WTP of 1.7 USD per person per month in a rural community while he found a WTP of 2.9 USD per person per month in the urban area. ${ }^{8}$

\subsubsection{Major Factors that Contribute to Willingness to Pay for Community Based Health Care Financing Scheme from Previous Studies.}

Previous studies have highlighted various factors that influence individuals and households 'WTP for CHI. The first of such factor is age ${ }^{17}$ A study in Ghana ${ }^{18}$ revealed that the premium level that individuals were willing to pay was related to age of the respondents. . The younger age group was willing to pay more. A similar finding in Namibia ${ }^{15}$ showed that theyoung respondents showed more interest in joining and WTP for the scheme. In a related related study in Tanzania, ${ }^{11}$ age of household head appeared to affect WTP because seventy-four percent of respondents who were not willing to pay any amount had household heads who were aged fifty and above.

Another important factor that affects WTP is gender. ${ }^{13}$ It was noted that males were willing to pay higher amounts for insurance than females in two different communities in Nigeria and in Ghana. ${ }^{19}$ closely related to these finding is the finding in Namibia ${ }^{20}$ where thirty-one percent of individuals who live in maleheaded households are insured compared with twenty-one percent of individuals living in female-headed households. This is however different from the finding in Tanzania where seventy-eight percent of households who were not willing to pay anything for CBHF had male household heads and twenty percent had female household heads. Although in this case most of the respondents who were not willing to pay any amount felt it was the government's responsibility to finance the program. The educational level of respondents also plays a significant role in their WTP. There is positive correlation between educational attainment and WTP. ${ }^{20}$ People with more education had a higher WTP.

Socioeconomic status also affects WTP. ${ }^{15}$ Less wealthy households or individuals were willing to pay lesser amounts. Other factors are household size, level of trust in those organizing the scheme, ${ }^{21}$ previous history of being involved in health insurance and history of large amount spent Out of pocket (OOP) for health ${ }^{8}$ Whilst 
previously paying OOP was negatively related to WTP, previously paying for health care using health insurance mechanism was positively related to WTP. ${ }^{8}$

\subsubsection{Comparison of Willingness to Pay and Factors Associated with Community Based Health Care Financing in Rural and Urban Areas.}

A study took place in Anambra and Enugu states, south-east Nigeria. ${ }^{8}$ It involved a rural, an urban and a semi-urban community in each of the two states. A pre-tested interviewer-administered questionnaire was used to collect information from a total of 3070 households selected by simple random sampling. Contingent valuation was used to elicit willingness to pay (WTP) using the bidding game format. Data were examined for correlation between SES and geographic locations with WTP. Log ordinary least squares (OLS) was used to examine the construct validity of elicited WTP.

Generally, less than $40 \%$ of the respondents were willing to pay for CBHI membership for themselves or other household members. The proportions of people who were willing to pay were much lower in the rural communities, at less than $7 \%$. The average that respondents were willing to pay as a monthly premium for themselves ranged from 250 Naira (US\$1.7) in a rural community to 343 Naira (US\$2.9) in an urban community. The higher the SES group, the higher the stated WTP amount. Similarly, the urbanites stated higher WTP compared with peri-urban and rural dwellers. Males and people with more education stated higher WTP values than females and those with less education.

\subsection{Description of the Study Area}

\section{Methodology}

Osun State is one of the thirty-six States in Nigeria. It is situated in the Southwestern part of the country and lies in the rainforest belt of the country with altitudes of between 121.92 and $298.70 \mathrm{~m}$ above the sea level. It is located within longitude $4^{\circ} 30^{\prime} \mathrm{E}$ and latitude $7^{\circ} 07^{\prime} \mathrm{W} 30^{\prime} \mathrm{N}$; with a landmass of $3571.8 \mathrm{~m}^{2}$. It has an estimated population of 3.2 million going by 2006 population census ${ }^{22}$ Osun State was created in 1991 from part of old Oyo State with its capital in Oshogbo. It is bounded in the north by Kwara state, in the east partly by Ondo State and partly by Ekiti State, in the south by Ogun state and in the west by Oyo State. It has three senatorial districts namely Osun central, Osun west and Osun East each comprising of ten local governments.

The population of Osun State is concentrated in a number of urban centers namely, Oshogbo, llesha, lleife, ljebuJesa, Ejigbo, Modakeke, lfetedo, Ede, lkirun, Ipetuljesa, lla and Ode-Omu. These urban centers are concentrated in the upper half of the state, while the smaller towns and villages are concentrated in the lower half .Even then ,there are farm camps between and surrounding the major urban centers of lle-ife, llesa, lla and Ipetujesa. The areas of major population concentration are lfe with population figure of over 185,000, followed by Irepodun and New Orolu Local Governments with populations of over 177,000; Ede has 147,000; llesa has 130,000 and Oshogbo Local Government, comprising mainly the capital, has a population of nearly 101,000 .

There are more than one thousand and thirty health facilities scattered throughout the state. ${ }^{23}$ Two of these are Tertiary Hospitals; Fifty-two are secondary Health care facilities; more than five hundred and thirty two Primary health care facilities managed by the thirty Local Governments with more than three hundred Private hospitals, some of these are owned by Missionaries.

2.2. Study Design: This is a comparative descriptive cross-sectional study.

\subsection{Study Population}

Head of households in the selected urban and rural communities in Osun State formed the study population.

3.3.1. Inclusion Criteria: All head of households that are adults ( $>18$ years) and are permanent resident of the areas.In case the head of household is not around any adult that is $>18$ years and permanent resident were interviewed.

2.3.2. Exclusion Criteria: All head of households who are less than 18years and are not permanent resident of the areas.

\subsection{Sample Size Determination}

The sample size was determined using the formula for calculating sample size for the comparison of two proportions . ${ }^{23}$

$\mathrm{n}=\underline{\mathrm{z}}_{1-\alpha / 2} \frac{\sqrt{2 p(1-p)}}{\left(\mathrm{p}_{1+\mathrm{p}_{2] 2}}\right.}+\underline{\mathrm{Z}-\beta} \frac{\sqrt{p 1(1-p 1)+p 2(1-p 2)}}{{ }^{2}}$

\section{Where}

$\mathbf{n}=$ Minimum sample size for each group

$\mathbf{Z 1 - \alpha / 2}=\quad$ Standard normal deviate corresponding to the probability of making type I error $(\alpha)$ at $5 \%=$ 1.96 


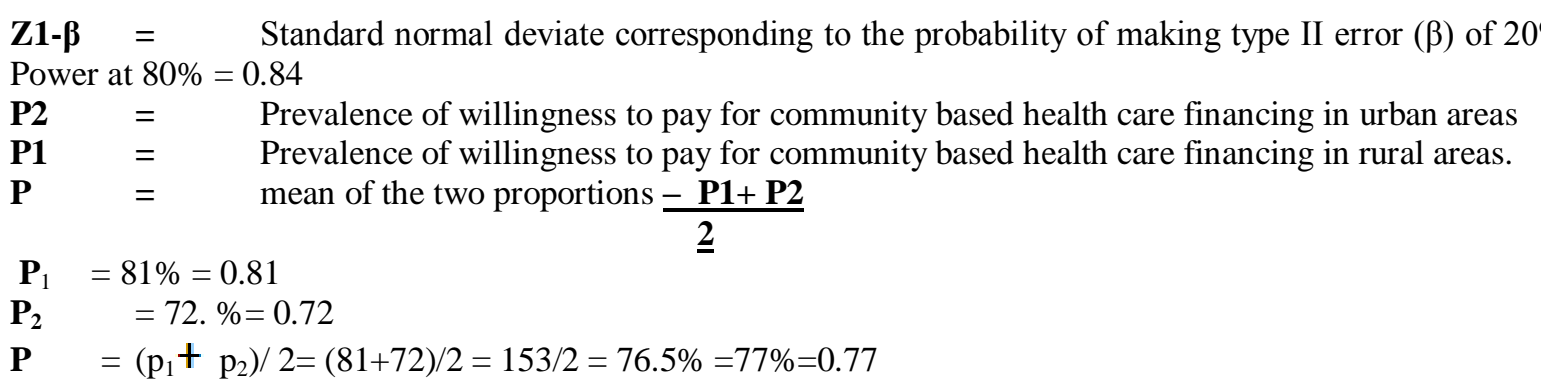

A previously published study documented the prevalence of willingness to pay for community based health care financing in urban and rural areas as $81 \%$ and $72 \%$ respectively $^{7}$

\section{Therefore}

$\mathbf{n}=\frac{\{1.96 \sqrt{ } 2(0.77)(1-077)+0.84 \sqrt{ } 0.81(1-0.81)+0.72(1-0.72)\}^{2}}{(0.81-0.77)^{2}}$

Assuming a non-response rate of $20 \%$

$\mathrm{n}=412$

The sample size was rounded up to 450 per group

\subsection{Sampling Technique}

Multistage sampling technique was used.

Stage1: A simple random sampling by balloting method was used to select a local government area from each of the three senatorial districts.

Stage2: One rural and one urban community each was selected using simple random sampling (by balloting) from each selected local government i.e. three urban and three rural communities.

Stage3: A sampling frame of all enumeration areas in each community were drawn using Federal Office of Statistics listing of 2006. Two enumeration areas (EAs) were selected from each of the selected rural and urban communities using simple random sampling utilizing ballot method. Proportional allocation of the sample size was done on each selected communities.

\begin{tabular}{llll} 
Name of sampled LGAS & Name of communities & EA selected & $\begin{array}{l}\text { No of households } \\
\text { sampled }\end{array}$ \\
\hline Irewole & Ikire(urban) & II & 185 \\
& Odeyinka(rural) & IV & 105 \\
\hline Osogbo & Okebale(urban) & III & 225 \\
& Ajenisua(rural) & II & 95 \\
\hline Ilesa east & Olomilagbala(urban) & IV & 210 \\
& Iwinkun (rural) & I & 80
\end{tabular}

Stage 4: The houses in each selected enumeration areas were counted and the number of houses needed was selected by simple random sampling by balloting without replacement in each community based on number of respondents needed in each community. The list of all households in each house (where there are more than one household living in a building) was generated and one of them was selected from the list by simple random sampling for questionnaire administration. A household is a group of persons who live together and eat from the same pot. The household head is the person responsible for leadership and financial decisions in the house.

\subsection{Study Instruments}

This was a pre-coded, semi structured questionnaires with close and open ended questions.Six visits to each of the rural and urban setting were made.The interviewer administered structured questionnaire which was divided into four section to collect relevant information were administered by ten trained research assistants.

\subsection{Data Collection Methods}

A qualitative data collection method was used.

\subsection{Statistical Analysis}

Questionnaires were checked for errors and omissions at the end of each day. Data were entered into the computer and analyzed with STATA10.0. ${ }^{24}$ Data error were checked for and corrected. The econometric model (Tobit model) of contingent valuation method for willingness to pay was adopted in this study for the 
multivariate analysis. Relevant frequencies, percentages, means and appropriate graphs and diagram was generated.

\subsection{Ethical Consideration}

A written approval from LAUTECH Teaching Hospital Research Ethical Review Committee was obtained.Introductory letters were sent to Osun State Ministry of Health,and to the selected local government authorities through their respective Medical Officers of Health.

The purpose and benefits of the research were highlighted during a written informed consent obtained from each of the community heads on community entry. During data collection,the objectives of the study were verbally explained to each respondent,and their cooperation and consent sought for before commencing the administration of the questionnaires during the course of this study.

\subsection{Study Limitation}

The study did not distinguish public and private health care providers in the willingness to pay questions; this could probably be the major limitation of the study.

\section{Results}

Table 1a: Socio-demographic Characteristics of Respondents by Place of Residence

URBAN

HOUSEHOLDS

\begin{tabular}{|c|c|c|c|c|}
\hline Variables & $\begin{array}{l}\text { Frequency } \\
(n=450)\end{array}$ & $\%$ & $\begin{array}{l}\text { Frequency } \\
(n=450)\end{array}$ & $\%$ \\
\hline \multicolumn{5}{|l|}{$\overline{\text { Age(yrs) }}$} \\
\hline $20-29$ & 64 & 14.2 & 44 & 9.7 \\
\hline $30-30$ & 168 & 37.3 & 82 & 18.2 \\
\hline $40-49$ & 81 & 18.0 & 100 & 22.2 \\
\hline $50-59$ & 62 & 13.8 & 163 & 36.2 \\
\hline$\geq 60$ & 75 & 16.7 & 61 & 13.6 \\
\hline Mean age & \multicolumn{2}{|l|}{$42 \pm 12.2 \mathrm{yrs}$} & \multicolumn{2}{|l|}{$47 \pm 10.2 \mathrm{yrs}$} \\
\hline \multicolumn{5}{|l|}{ Gender } \\
\hline Male & 304 & 67.7 & 352 & 78.2 \\
\hline Female & 146 & 32.3 & 98 & 21.8 \\
\hline \multicolumn{5}{|c|}{ Marital Status } \\
\hline Single & 29 & 6.5 & 26 & 5.8 \\
\hline Married & 320 & 71.7 & 313 & 69.6 \\
\hline Seperated & 55 & 12.2 & 48 & 10.7 \\
\hline Widow(er) & 46 & 10.2 & 6.3 & 14.0 \\
\hline \multicolumn{5}{|c|}{ Educational status } \\
\hline$\leq$ primary & 79 & 17.5 & 256 & 56.9 \\
\hline Secondary & 137 & 30.5 & 139 & 30.9 \\
\hline Tertiary & 234 & 52.0 & 55 & 12.2 \\
\hline
\end{tabular}

\section{Occupation}

Students

Artisan

Civil Servants

Traders

Farmers

Unemployed
234
RURAL

HOUSEHOLDS

78.2

8

69.6

10.7

56.9

12.2

7.1

20.0 
Table 1b: Monthly Income of Respondents by place of Location

URBAN

HOUSEHOLDS
RURAL

HOUSEHOLDS

\begin{tabular}{|c|c|c|c|c|}
\hline Monthly Income(in Naira) & Frequency $(n=422)$ & $\%$ & Frequency $(n=429)$ & $\%$ \\
\hline$\leq 5000$ & 58 & 13.7 & 134 & 31.2 \\
\hline $5001-10000$ & 40 & 9.5 & 128 & 29.8 \\
\hline $10001-15000$ & 83 & 19.7 & 95 & 22.2 \\
\hline $15001-20000$ & 110 & 26.1 & 48 & 11.2 \\
\hline$>20000$ & 131 & 31.0 & 24 & 5.6 \\
\hline
\end{tabular}

Mean

$42 \pm 5,200$

$10 \pm 5,300$

Table 2: Average Family Size per Households by Place of Residence

URBAN

HOUSEHOLDS
RURAL HOUSEHOLDS

\begin{tabular}{llllc}
\hline $\begin{array}{l}\text { Number in } \\
\text { Household }\end{array}$ & $\begin{array}{l}\text { Frequency } \\
(\boldsymbol{n = 4 5 0 )}\end{array}$ & \% & $\begin{array}{l}\text { Frequency } \\
(\mathbf{n = 4 5 0 )}\end{array}$ & \% \\
\hline $1-3$ & 112 & 24.9 & 60 & 13.3 \\
$4-6$ & 237 & 52.7 & 152 & 33.8 \\
$7-9$ & 86 & 19.1 & 184 & 40.9 \\
$>10$ & 15 & 3.3 & 54 & 12.0 \\
Mean Household & $\mathbf{4} \pm \mathbf{2 . 2}$ & & $\mathbf{5 \pm 3 . 2}$ & \\
Size & & & &
\end{tabular}

Table 3: Willingness to pay for Community Based Health Care Financing Scheme by Place of Location

\begin{tabular}{llccc}
\hline Willingness to pay & Rural & \% & Urban & \% \\
\hline $\begin{array}{l}\text { Willing to pay for } \\
\begin{array}{l}\text { CBHF } \\
\text { Not willing to pay } \\
\text { for CBHF }\end{array}\end{array}$ & 373 & 82.8 & 232 & 51.6 \\
\hline Total & 77 & 17.2 & 218 & 48.4 \\
\hline
\end{tabular}

Table 3 shows: willingness to pay for CBHF by place of location. Two hundred and thirty-two (51.6\%) of urban households were willing to pay for community based health care financing scheme while 218 (48.4\%) households were not willing to pay.

Three hundred and seventy-three $(82.8 \%)$ of rural households were willing to pay for community based health care financing scheme while $77(17.2 \%)$ households were not willing to pay.

Figure i shows: Premium respondents were WTP for CBHF per person per year. Thirty-eight (54.0\%) of rural respondents were WTP $\leq \$ 500$ as compared to $14(10.0 \%)$ of the urban respondents. Similarly, 17(24.0\%) of rural respondents were WTP between $\$ 500-1000$ compared to $17(12.0 \%)$ in the urban, households. Fifteen (32.0\%) of rural respondents were willing to pay between $\$ 1,000-1,500$ compared to52 (37.0\%) in the urban respondents. 57(41.0\%) of urban respondents were WTP $\$ 1,501$ and more while rural respondents were not willing to pay up to this amount.

Table 4: Distribution of Respondents according to Amount Willing to pay in Urban Households

\begin{tabular}{lll}
\hline Measures & $\begin{array}{l}\text { Cash } \\
\text { (in Naira) }\end{array}$ \\
\hline & & \\
Minimum & 500.00 & \\
Mean & $1,798.90$ & 34 Page \\
Median & $1,200.00$ & \\
Mode & $1,500.00$ & \\
Standard deviation & 134.50 & www.iosrjournals.org
\end{tabular}




$\begin{array}{ll}\text { Maximum } & 3,500.00 \\ \text { Range } & 3,000.00\end{array}$

Table 4 shows: Distribution of respondents according to amount willing to pay in urban households. The mean WTP for urban households was $\$ 1,798.90 \mathrm{k}$ per person per year, the minimum WTP was $\$ 500.00 \mathrm{k}$ and the maximum WTP was $3,500.00 \mathrm{k}$.

Table 5: Distribution of respondents according to Amount Willing to Pay in Rural Households.

\begin{tabular}{ll}
\hline Measures & $\begin{array}{c}\text { Cash } \\
\text { (in Naira) }\end{array}$ \\
\hline Minimum & 50.00 \\
Mean & 721.70 \\
Median & 500.00 \\
Mode & 300.00 \\
Standard deviation & 250.50 \\
& \\
Maximum & $1,000.00$ \\
Range & 950.00
\end{tabular}

\begin{tabular}{lll}
\hline Range WTP & $250.50-972.20$ \\
\hline
\end{tabular}

Table 5 shows: Distribution of respondents according to amount willing to pay in rural households. The mean WTP for rural households was $\$ 21.70 \mathrm{k}$ per person per year, the minimum WTP was $\$ 50.00 \mathrm{k}$ and the maximum WTP was 1,000.00k.

Table 6: Result of Tobit Analysis of Explanatory Variables for Rural Respondents.

Log likelihood $=-101.06636$

Number of observation $=373$

$\operatorname{Pr}>$ chi $^{2}=0.004$

Pseudo $\mathrm{R}^{2}=0.973$

$\operatorname{LR~}_{\operatorname{chi}}{ }^{2}(7)=21.78$

\begin{tabular}{llll}
\hline Variables & Coefficient & Std.err & pvalue \\
\hline Number in households & 2.933626 & 2.913768 & 0.279 \\
\hline Age & 0.128385 & 0.171348 & $0.001^{*}$ \\
\hline Income & -5.323841 & 1.801133 & $0.000^{*}$ \\
\hline Distance to health facilities & -1.791142 & 0.790324 & $0.002^{*}$ \\
\hline Level of education & 5.832498 & 0.101625 & 0.540 \\
\hline Marital status & 1.805619 & 0.587662 & $0.000^{*}$ \\
\hline Male & 3.084466 & 1.175420 & $0.000^{*}$ \\
\hline Constant & 0.748852 & 0.586067 & 0.201 \\
\hline
\end{tabular}

$\mathrm{P}<0.05 *$ Significant factors affecting willingness to pay

The factors identified contributing to willingness to pay in the rural communities were shown in the table above. One of the factor was age, a unit increase in age will increase WTP by $17 \%$, which mean the elderly, are more willing to pay for CBHF.

Income was also found to be significant with a negative signs which means a unit increase in income will decrease WTP by $53 \%$ i.e. the rich are less WTP.

Distance to health centers was also found to be a contributing factor to WTP for CBHF with a unit increase in distance decreasing WTP by $18 \%$ respectively. That is the farther the distance to the health centers the lesser the WTP to to pay for CBHF. 
Table 7: Result of Tobit Analysis of Explanatory Variables for Urban Respondents.

Log likelihood $=-95.381571$

Number of obs $=232$

${\operatorname{LR~} \operatorname{chi}^{2}}^{2}(7)=22.22$

\author{
$\begin{aligned} & \text { Pseudo } \mathrm{R}^{2}=0.5 \\ & \text { Prob }>\text { chi }^{2}=0.0031\end{aligned}$
}

\begin{tabular}{llll}
\multicolumn{1}{c}{ Cash } & \multicolumn{3}{l}{} \\
\hline Variables & Coefficients & Std.err & pvalue \\
\hline Number in households & 1.011375 & 0.898553 & $0.000^{*}$ \\
\hline Age & -0.767831 & 0.559157 & $0.000^{*}$ \\
\hline Income & 0.777687 & 0.989325 & $0.000^{*}$ \\
\hline Distance to health facilities & -1.124885 & 0.514228 & $0.001^{*}$ \\
\hline Level of education & 2.722616 & 0.727444 & $0.000^{*}$ \\
\hline Marital status & 0.881185 & 0.507493 & $0.002^{*}$ \\
\hline Male & 0.543270 & 0.321323 & $0.000^{*}$ \\
\hline Constant & 0.527104 & 0.324560 & 0.032 \\
\hline
\end{tabular}

$\mathrm{P}<0.05 *$ significant factors affecting willingness to pay

Results of the estimation of factors affecting willingness to pay for community based health care financing scheme in urban households were summarized and presented above. Age was another factor found to be statistically significant with a negative sign i.e. a unit in age will decrease the WTP by $76 \%$ which means the elderly are less WTP .

Distance to the health center was found to be contributing to WTP, a unit increase in distance increase WTP by $11 \%$. Marital status also increases WTP; the married people are 51\% more WTP for community based health care financing. Level of education is another important factor which that contributed to WTP, the higher the level of education the higher the WTP for the use of cash while for the use of commodities the reverse was the case i.e. the less educated were more willing to pay with commodities .Being a male head of household increases WTP by $54 \%$.

\title{
IV. Discussion
}

The socio-demographic characteristics of respondents shows that the mean age of heads of household was $42 \pm 12.2$ years and $47 \pm 10.2$ years for urban and rural households respectively. Two-third of head of households in both settings were male which is characteristics of most African settings. ${ }^{19}$ This is also in line with Nigeria demographic and health survey $2008 .^{25}$

More than two-third of the household heads from both communities were married, while more than one-tenth were separated and about six percent were single and others were widow(er) in both communities. Fifty-two percent of the urban heads of households had tertiary education as compared to twelve percent in the rural households, this shows there is high level of literacy in the urban communities which is characteristics of many urban communities in Nigeria. Only about half (57.0\%) of rural household respondents had primary education or below as compared to one tenth in the urban households, this also shows low level of literacy in the rural communities which is also characteristics of rural communities in Nigeria and this also in line with Nigeria demographic survey 2008 which had $48.9 \%$ of rural population of Nigeria with no education compared with urban of $22 \% .{ }^{25}$ Majority of urban household heads were civil servants $(36.7 \%)$ while farming was the major occupation in the rural households (53.6\%). Almost all the household heads were earning income monthly with mean income for urban heads to be $42 \pm 5,200$ and $\$ 10 \pm 5,300$ for rural heads as compared with a study in Enugu where majority of household heads were employed in Local Government jobs and others were into farming and the average household income was $\$ 10,141.20 \mathrm{k}$ per month for rural households. ${ }^{19}$ The average household size was $4 \pm 2.2$ for urban households and $5 \pm 3.3$ for rural households which is similar to result from a study in Ilorin North Central where household size average was $5.0 \pm 2.7^{31}$ and also the Nigeria demographic and health survey where the mean household size for urban households was 4.1 and 4.6 for rural households. ${ }^{25}$

Only about half $(52.0 \%)$ of the urban households were willing to pay for community based health care financing scheme as compared to the majority (83.0\%) of rural households willing to pay for community based health care financing scheme. This is contrast to what Onwujekwe et al ${ }^{8}$ found in the Eastern part of the country, this may be as a result of difference in the geo-political zones and also cultural difference in the two regions, whereby the rural people in South Western part are used to "Ajo","Esusu" e.t.c. A study from North central part of Nigeria ${ }^{26}$ found $87 \%$ willingness to pay for community health insurance among rural households which is in line with the findings from this study. One would expect higher willingness to pay from urban households as evidenced by level of income, literacy level, e.t.c but reverse was the case this may be as a result of lack of access to quality health care in the rural communities as compared to the urban centers thereby raising their interest in a programme that will improve their access to good health care. Also because of strong earning power in the urban setting they may think they can afford the user fee anytime the need arises. 


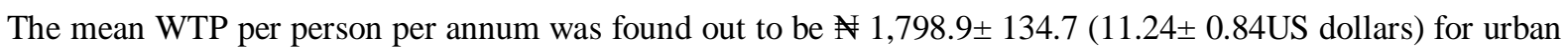
households with the usage of cash while in the rural households it was found to be $\$ 721 \pm 250.5$ (4.51 \pm 1.57USD). In Eastern Nigeria, Onwujekwe et al ${ }^{8}$ found a WTP of 250 naira per month per person in rural communities for community health insurance ( $\mathrm{CHI}$ ) this is equivalent to 3,000 naira per person per year. This disparity may be because of the differences in geo-political area and cost of living in both locations. Ichoku et al found a WTP of 1.5 USD per household per month. ${ }^{16}$ On the other hand Onwujekwe et al in a Nigerian survey found WTP of 1.7 USD per person per month in a rural community while he found a WTP of 2.9 USD per person per month in the urban area. ${ }^{8}$ Another similar survey by Babatunde et al in Ilorin, Kwara state ${ }^{26}$ reported mean WTP of $3.48+1.78$ US dollars person per annum for CHI in a community with average household size of 6 members. This is also similar to the finding from this study which revealed a mean of $4.51 \pm$ 1.57US dollars for rural households.

In Wuhan, China, Barnighausten et al ${ }^{10}$ found that the mean WTP among informal sector workers was an equivalent of 4 US dollars per person per month for CHI (48 US dollars per person per year). This difference compared to our finding might be because of the differences in prevailing socio-economic situations and level of industrialization which obviously will affect the earning power. In a similar study on WTP for a school based chemotherapy program in Tanzania, greater than seventy percent had WTP greater than 1.25 US dollars per person per year while the median WTP was 1.25 US dollars. ${ }^{13}$ This is much lower compared to the finding in thisstudy. The difference might be because the health package in this Tanzania study is limited to school based chemotherapy program only and not complete basic health package as was done in this study.

Age was also a important factor that was statistically significant with the use of cash but with a negative sign implying that the elderly are less willing to pay higher amount for CBHF as compared to the younger respondents. The findings from this study is in line with a study from Nsukka. ${ }^{19}$ Another study by Dong found that the elderly were less willing to pay than the the younger respondents were WTP which the result of this study confirmed by decrease in WTP of 76\% among the elderly. This can be explained that the pay-off period for any human capital investment in health at older ages yield less and lesser compared to the younger respondents. ${ }^{27}$

Age was another factor identified because it was found to be statistically significant in the rural households. For a unit increase in age will increase WTP by $17 \%$ i.e. the elderly were more WTP.

Income was found to be important as a unit increase in income increases WTP by 77\% . The economic intution behind this suggest that income is a very important variable in determining the demand for any good. This finding with respect to income has been the debate and argument about the WTP approach in health care valuation as the amount households or respondents are WTP is an increasing function of their ability to pay. According to the study carried out in india among 3000 households on health insurance, about half of the respondents are willing to pay $1.35 \%$ of their annual income and a positve relationship exist betwwen household income and willingness to pay. ${ }^{11}$ In the same vein, a study in China ${ }^{28}$ found out that richer household are more willing to pay higher amounts than the poorer households which is in agreement with what is found in this study. Income was also found to be statistically significant in rural households with a negative sign which means a unit increase will reduce WTP by $53 \%$ i.e. the richer are less willing to pay .

Distance travelled to access health care also affected the WTP, as a unit increase in distance decrease WTP by $11 \%$, this pointed out that people want to access health care close to them as much as possible and this is also in line with principles of primary health care which says that the distance from home to a health center should be $\leq 60 \mathrm{~km} .{ }^{25}$ A study from Ghana showed that distance to the nearest health facilities had the hypothesized sign and significance indicating that accessibility of health care will induce demand for community based health care financing which also in agreement with the findings from this study. ${ }^{29}$

Distance to the health center was also important in the rural households, as a unit increase in distance decreases WTP by $18 \%$ i.e. the farther the distance to the health center the lesser the WTP because people will want closer access to health care.

Level of education was found to be another factor contributing to willingness to pay an increase that there is positive association between years of schooling and WTP for community based in the level of was found to increase WTP by $27 \%$ with the use of cash i.e. the more educated households were willing to pay higher amount . Some studies have shown that there is a positive correlation between educational attainment and WTP. ${ }^{11}$ Another study which found that education plays a statistically significant role in determining the decision of respondents for WTP, it stated the marginal coefficient of education variable showed that a one grade increase in the highest grade completed will increase the probability of respondents to pay by $0.6 \% .{ }^{15}$ Level of education was also found to be important in the rural households, as a unit increase in the level of education increases WTP by 58\% with use of cash i.e. the more educated in the rural communities the higher the WTP while for the use of cash this was found to be insignificant. 
Being a male head of household also increases WTP by $54 \%$ with the use of cash .It was noted that males were willing to pay higher amounts for insurance than females in two different communities in Nigeria and in Ghana. ${ }^{8,30}$ Closely related to these findings is the finding in Namibia ${ }^{15}$ where thirty-one percent of individuals who live in male-headed households were insured compared with twenty-one percent of individuals living in female-headed households. This may be as a result of men being the bread winners in most African countries while most household headed by females are usually widows. This is however contrary from the finding in Tanzania ${ }^{11}$ where seventy-eight percent of households who were not willing to pay anything for CHBF had male household heads and twenty percent had female household heads. Although in this case most of the respondents who were not willing to pay any amount felt it was the government's responsibility to finance the program. For the rural households, gender was also significant with being a male household increasing WTP by $12 \%$,females were less WTP this may be as result of female heads being widows and most are engaged in farming for sustenance in the rural communities.

Marital status was found to increases WTP by $51 \%$.i.e married head of households were more WTP than the single and divorced. Some studies have shown that marital status influences the behavior of individuals towards health services ${ }^{31}$ which also is in line with the finding from this study.

The rural households $(82.8 \%)$ were more willing to pay for community based health care financing than the urban households (61.6\%), this was found to be statistically significant. This is contrary to the findings of Onwujekwe et.al ${ }^{8}$ in Eastern part of Nigeria where $<7 \%$ of rural households were WTP but a study in North central part of Nigeria found 87\% WTP among the rural household in this area which is similar to the result from this study. High rate of willingness among the rural households may as result of lack of health facilities in most of these rural communities in Osun state as well as Nigeria as a whole. The findings from one study carried out in rural areas of Osun State indicates that the available healthcare facilities are grossly inadequate and their distribution depicts serious inequality and concluded that there is an urgent need for serious intervention on the part of the government in the provision of health care facilities in the state focused on equitable distribution and accessibility to enhance sustainable rural development. ${ }^{29}$ This is also supported by a study done by Saanni in which he found out that there is an existing gap between in access to health care facilities between local and urban areas. ${ }^{32}$

Factors identified to affect or contribute to willingness to pay among rural and urban households were similar but mostly different in terms of mode of payment. For instance number in households was significant for the use of cash in the urban households, thereby showing us that there is gap in the socio-economic status of the urban and rural households and making it comfortable for the rural household to pay with what they have.

In terms of age, in the urban areas the younger age groups were more willing to pay compared to the elderly that were more willing to pay in the rural households and this may be due to the younger age group being active and still productive whereas most elderly people usually retire at their villages after active services and most times engaged in farming.

In terms of amount earned per month or income, in urban areas the richer they were the lesser they were willing to pay as compared with the rural areas that as their increases their willingness to pat also increases. This again shows that the rural areas are really in need of accessible and affordable health care. The urban household that were less willing still have access to health care although not adequate but they are not starved as rural households.

Distance to health center was also an important factor and the willingness to pay increases with increase in distance to the health center for the urban households which means they could only value the payment if the accessibility is not within the reach unlike the rural households.

\section{Conclusion}

Appreciable number of respondents shows positive WTP and this shows that many respondents saw the value of the scheme and recognized that CBHF may increase access to good quality health services for themselves and for members of their family, without having to pay at the point of use and with CBHF spreading payments over time .

The implication of low levels of average WTP amounts is that the amount of money that will be The implication of low levels of average WTP amounts is that the amount of money that will be available for the schemes when established will be low, unless there is external financial support. If, for example, 1,798.90 and 721.70 Naira per urban and rural member is the minimum expected annually, then the elicited mean WTP amounts pose challenges for the viability and sustainability of such schemes.

To design a feasible and attainable community based health care financing scheme for the people of Osun State, quantitative data is needed and required as a guide to aid Osun State government and stakeholders in an optimal decision making path. These data can be obtained through contingent valuation method using the willingness to pay approach. 


\section{Recommendations}

(1) Based on the high willingness to participate in Community based health care financing scheme, the community-based health care financing scheme seem to be feasible in the study areas. Pilot schemes could be initiated in the selected areas and lessons learnt from the experience of this pilot can be applied to other localities.

(2) The premium to be charged should be anchored around reported measures of central tendencies gotten from this study ( $\$ 721.7$ and 1798.9).

(3) There will also be a need for the government to subsidize the programme so that much funds can be pooled for sustainability of the programme.

(4) The scheme can be further intergrated into microfinance schemes such as the case in India and Bangladesh with SEWA and the Grameen banks respectively.

(5) Women and elderly were less willing to pay for this proposed scheme therefore in establishing community based health care financing scheme there should be selective targeting of the vulnerable groups within the communities.

\section{References}

[1]. Arkin-Tenkorang,DC.Health Insurance for the Informal Sector in Africa:Designing features,risk protection and resource mobilization, Health,Nutrition and Population(HNP) Discussion Paper,World Health Organization,2001, Washighton D.C.

[2]. Asenso-okyere Wk, Osei-Akoto,I.Willingness to pay for health Insurance in a developing economy.A pilot study of informal sector of Ghana using Contingent valuation.Health policy,42(1997):223-237.

[3]. WHO. Country cooperation strategy: Federal republic of Nigeria, 2002-2007. Geneva Switzerland:WHO;2007

[4]. World development report (2005). World development indicators: country: Nigeria. Accessed on 24 Febuary, 2012. Available atwww.worldbank.org/external/countries/africa ext/nigeriaextn.

[5]. Adinma ED, Adinma BJ. Community Based healthcare financing: An untapped option to effective healthcare funding in Nigeria. Nigeria Med J 2010; 51:95-100.

[6]. Partners for Health Reform Plus, 21 questions on CBHF, An Overview of Community-Based Health Financing. March 2004.

[7]. Masud TI, Farooq N. Equity shortfalls and Welfare State: Willingness to pay for health care at Government facilities in Jhelum. J.Ayub Med Coll Abbottabad 2003,15(4):43-49.

[8]. Onwujekwe O, Okereke E, Onoka C, Uzochukwu B, Kirigiaand J , Petu A. Willingness to pay for community-based health insurance in Nigeria: Do economic status and place of residence matter? Health Policy Planning, 2010; 25(2): 155-161.

[9]. Babatunde OA, Akande TM, Salahudeen AG, Aderibgbe SA, Elegbede OE, Ayodele LM. Willingness to pay for community health insurance and its determinants among household heads in rural communities in North Central Nigeria. International review of Social Sciences and Humanities $2012 ;(2): 133-142$.

[10]. Barnighausten T, Liu X, Zang X, Sauerborn R. Willingness to pay for social health insurance among informal workers in Wuhan, China: A contingent valuation study, London Biomed Central Health Services Research, 2007.

[11]. Dror DM, Radermacher R, Koren R. Willingness to pay Health Insurance Units in India. Field evidence from seven micro health insurance units in India. Health Policy 2007; 82: 176-181.

[12]. Asgary A, Willis K, Taghvaei A, Rafeian M. Estimating Rural Households' Willingness to pay for Health Insurance. European Journal of Health Economics aaasGZF2004; 5: 209-215.

[13]. Lwambo NJ, Siza JE and Mwenda GC. Community's willingness to pay for a school-based chemotherapy program to control morbidity due to schistosomiasis and soil-transmitted helminthiasis in children in rural Tanzania, Tanzania Health Research Bulletin, 2005; 7: 149-153.

[14]. Lewalen S. Geneau R. Mahande M. Msangi J, Nyumpumbwe S, Kitumba R. Willingness to Pay for cataract surgery in two regions of Tanzania, Br J Ophthalmol, 2006; 90(1):11-13.

[15]. Asfaw A, Gustafson-Wright E, VanderGaag J. Willingness to pay for health insurance: An analysis of the potential market for new low-cost health insurance products in Namibia, Amsterdam Institute for International Development 2008; AIIDRS - 08 01/2: 1-22.

[16]. Ichoku E.H, Fonta W and Atagbua J. Estimating the willingness to pay for community health insurance schemes in Nigeria: A random valuation framework, The IUP Journal of Risk and Insurance, 2010;7(1):7 -27.

[17]. John T. Affordable Health Insurance for All Is Possible by Means of a Pragmatic Approach. Am J Public Health.2003; 93(1):106109 .

[18]. Edoh B and Brenya A. A Community-based feasibility study of National Health Insurance in Ghana. Afr J Health Sci., 2002;9(12): $41-50$

[19]. Ataguba JE. Community Health Insurance Scheme as a viable option for rural population in Nigeria. Center for the study of African Economies CSAE 2008; JEL Classification I10, I38, D11: 1-11.

[20]. Sonali K. Community health financing, Regional health forum WHO South-east Asia region, 2009, 8(1):65-68.

[21]. Toonen, J. Community financing for health care: A case study from Bolivia.Royal Tropical Institute, Amsterdam Bulletin No 337

[22]. Federal Republic of Nigeria. Federal Republic of Nigeria official Gazette of the 2006 National population and housing census. The Federal Government Printer Lagos, Nigeria FGP 71/52007/2, 500(OL24). 2007; 94(24): 175-198.

[23]. Bamigboye AE. Sample size determination: A Companion of Medical Statistics. Folbam Publishers, Samonda, Ibadan, Oyo State, Nigeria 2007:141-155.

[24]. STATA 10. Stata Data Analysis 10.0, serial number 81910043720, Statacorp 4905 Lake way Drive college station, Texas 77845 USA. Tobin J, Estimation of relationship for limited dependent variables, Econometrics, 1958; (26):24-32.

[25]. Nigerian Population Commission. Federal Republic of Nigeria, Nigerian Demographic and Health Survey 2008, Preliminary Report MEASURE DHS, ICFMacro Calverton, Maryland USA, (2009), 1-37.

[26]. Babatunde OA, Akande TM, Salahudeen AG, Aderibgbe SA, Elegbede OE, Ayodele LM. Willingness to pay for community health insurance and its determinants among household heads in rural communities in North Central Nigeria. International review of Social Sciences and Humanities $2012 ;(2): 133-142$.

[27]. Dong H, Kouyate B, Caims J, Mugicha F, and Sauerborn R. Willingness to pay for community-based insurance in Burkina Faso. Health Economics. 2003a ;12: 849-862. 
[28]. Lang H, Lai M. Willingness to pay to sustain and expand National health insurance services in Taiwan. BMC Health Services Research. 2008; (3): 261.

[29]. Ajala O.A, Lekan S, Adeyinka S.A. Accessibility to Healthcare facilities; a panacea for sustainable rural Development in Osun state Southwestern Nigeria. J. Hum Ecol. 2005; 18(2):121-128.

[30]. Edwar NA. Demand for health insurance among women in Ghana: cross sectional evidence. International Research Journal of Finance and Economics. 2009;33:145-287

[31]. Asgary A, Willis K, Taghvaei A, Rafeian M. Estimating Rural Households' Willingness to pay for Health Insurance. European Journal of Health Economics aaasGZF2004; 5: 209-215.

[32]. Saanni L. Distribution pattern of health care facilities in Osun State, Nigeria. Ethiopian Journal of Environmental Studies and Management. 2010;3(2):65-76.

\section{SUMMARY BOX}

'What is already known on this subject: Community Based Health Care Financing has been an option of financing health care which gives opportunity to community members to have access to quality health care at a price that is affordable cost. This has been practiced in many low income countries like Nigeria which Osun State is inclusive.

What does this study add? The findings from this study suggest that people are willing to pay for community based health care financing scheme especially in the rural communities. Establishing this scheme in Osun state is feasible, so pilot study can be done with some communities' before commencement in the whole State. 